\title{
Prognostic factors associated with upper gastrointestinal bleeding based on the French multicenter SANGHRIA trial
}

\section{(ㄷ)(우우}

\section{Authors}

Vincent Quentin', André-Jean Remy², Gilles Macaigne ${ }^{3}$, Rachida Leblanc-Boubchir ${ }^{4}$, Jean-Pierre Arpurt ${ }^{5}$, Marc Prieto ${ }^{6}$, Carelle Koudougou ${ }^{7}$, Laurent Tsakiris ${ }^{8}$, Denis Grasset ${ }^{9}$, René-Louis Vitte ${ }^{10}$, David Cuen ${ }^{11}$, Juliette Verlynde ${ }^{12}$, Khaldoun Elriz ${ }^{13}$, Marie-Pierre Ripault ${ }^{14}$, Florent Ehrhard ${ }^{15}$, Mathieu Baconnier ${ }^{16}$, Sofia Herrmann ${ }^{17}$, Nathalie Talbodec $^{18}$, You-Heng Lam ${ }^{19}$, Karine Bideau ${ }^{20}$, Laurent Costes ${ }^{21}$, Florence Skinazi ${ }^{22}$, Ivan Touze ${ }^{23}$, Denis Heresbach ${ }^{24}$, Pierre Lahmek ${ }^{25}$, Stéphane Nahon ${ }^{26}$, Members of the Association Nationale des Hépato-gastroentérologues des Hôpitaux Généraux (ANGH) SANGHRIA Study Group

Institutions

1 Department of Gastroenterology, Centre Hospitalier $(\mathrm{CH})$ de Saint-Brieuc, Saint-Brieuc, France

2 Department of Gastroenterology, $\mathrm{CH}$ de Perpignan, Perpignan, France

3 Department of Gastroenterology, $\mathrm{CH}$ de Marne-laVallée, Marne-la-Vallée, France

4 Department of Gastroenterology, $\mathrm{CH}$ de Valenciennes, Valenciennes, France

5 Department of Gastroenterology, $\mathrm{CH}$ d'Avignon, Avignon, France

6 Department of Gastroenterology, $\mathrm{CH}$ de Meaux, Meaux, France

7 Department of Gastroenterology, $\mathrm{CH}$ de La Roche-surYon, La Roche-sur-Yon, France

8 Department of Gastroenterology, $\mathrm{CH}$ de Melun, Melun, France

9 Department of Gastroenterology, CH de Vannes, Vannes, France

10 Department of Gastroenterology, CH de Poissy, Poissy, France

11 Department of Gastroenterology, CH de Saint-Malo, Saint-Malo, France

12 Department of Gastroenterology, $\mathrm{CH}$ de Dunkerque, Dunkerque, France

13 Department of Gastroenterology, CH de Corbeil, Corbeil, France

14 Department of Gastroenterology, CH de Béziers, Béziers, France

15 Department of Gastroenterology, CH de Lorient, Lorient, France

16 Department of Gastroenterology, CH d'Annecy, Annecy, France

17 Department of Gastroenterology, CH d'Orléans, Orléans, France

18 Department of Gastroenterology, CH de Tourcoing, Tourcoing, France

19 Department of Gastroenterology, $\mathrm{CH}$ de Cholet, Cholet, France
20 Department of Gastroenterology, CH de Quimper, Quimper, France

21 Department of Gastroenterology, CH de Créteil, Créteil, France

22 Department of Gastroenterology, CH de Saint-Denis, Saint-Denis, France

23 Department of Gastroenterology, CH de Lens, Lens, France

24 Department of Gastroenterology, $\mathrm{CH}$ de Pontivy, Pontivy, France

25 Department of Gastroenterology, $\mathrm{CH}$ de LimeilBrévannes, Limeil-Brévannes, France

26 Department of Gastroenterology, CH de Montfermeil, Montfermeil, France

submitted 7.1.2021

accepted after revision 5.5.2021

Bibliography

Endosc Int Open 2021; 09: E1504-E1511

DOI 10.1055/a-1508-5871

ISSN 2364-3722

(C) 2021. The Author(s).

This is an open access article published by Thieme under the terms of the Creative Commons Attribution-NonDerivative-NonCommercial License, permitting copying and reproduction so long as the original work is given appropriate credit. Contents may not be used for commercial purposes, or adapted, remixed, transformed or built upon. (https://creativecommons.org/licenses/by-nc-nd/4.0/)

Georg Thieme Verlag KG, Rüdigerstraße 14,

70469 Stuttgart, Germany

Corresponding author

Vincent Quentin, MD, Service d'Hépato-Gastroentérologie, Hôpital Yves-Le-Foll, 10 rue Marcel-Proust, 22000 Saint-

Brieuc, France

Fax: $+33(0) 296017475$

vincent.quentin@ch-stbrieuc.fr 


\section{ABSTRACT}

Background and study aims Prognostic and risk factors for upper gastrointestinal bleeding (UGIB) might have changed overtime because of the increased use of direct oral anticoagulants and improved gastroenterological care. This study was undertaken to assess the outcomes of UGIB in light of these new determinants by establishing a new national, multicenter cohort 10 years after the first.

Methods Consecutive outpatients and inpatients with UGIB symptoms consulting at 46 French general hospitals were prospectively included between November 2017 and October 2018. They were followed for at least for 6 weeks to assess 6 -week rebleeding and mortality rates and factors associated with each event.

Results Among the 2498 enrolled patients (mean age 68.5 [16.3] years, $67.1 \%$ men), $74.5 \%$ were outpatients and $21 \%$ had cirrhosis. Median Charlson score was 2 (IQR 1-4) and Rockall score was 5 (IQR 3-6). Within 24 hours, $83.4 \%$ of the patients underwent endoscopy. The main causes of bleeding were peptic ulcers $(44.9 \%)$ and portal hypertension $(18.9 \%)$. The early in-hospital rebleeding rate was $10.5 \%$. The 6 -week mortality rate was $12.5 \%$. Predictors significantly associated with 6-week mortality were initial transfusion (OR 1.54; $95 \% \mathrm{Cl} 1.04-2.28$ ), Charlson score $>4$ (OR 1.80; 95\%Cl 1.31-2.48), Rockall score > 5 (OR 1.98; $95 \%$ $\mathrm{Cl} 1.39-2.80$ ), being an inpatient (OR 2.45; 95\%Cl 1.76$3.41)$ and rebleeding (OR 2.6; $95 \% \mathrm{Cl} 1.85-3.64)$. Anticoagulant therapy was not associated with dreaded outcomes. Conclusions The 6-week mortality rate remained high after UGIB, especially for inpatients. Predictors of mortality underlined the weight of comorbidities on outcomes.

\section{Introduction}

During the past decade, European and American endoscopy and hepatology societies have updated their guidelines concerning the management of variceal or non-variceal upper gastrointestinal bleeding (UGIB) to improve gastroenterological care and ultimately patient outcomes [1-4]. Nevertheless, UGIB remains a frequent health problem with a mortality rate that remains high $[5,6]$.

The first prospective, national, multicenter study was conducted in 53 French general hospitals in 2005 and included 3203 outpatients [7] with a mortality rate of $8.3 \%$. Independent predictors of mortality were Rockall score, comorbidities, and systolic blood pressure $<100 \mathrm{~mm} \mathrm{Hg}$ at first consultation. A substudy on bleeding peptic ulcers showed a slight decrease in UGIB-linked mortality, attributed to improved prevention, better adherence to guidelines, and better comorbidity support [8].

Potential risk and prognostic factors for UGIB may have evolved in developed countries, particularly with the increased use of direct oral anticoagulants to treat thromboembolic diseases, improved gastroenterological management with the use of new effective endoscopic hemostatic devices, and in some countries, the development of expert regional endoscopic care. UGIB-associated prognostic factors in this context have been investigated in only a few studies, and most of the recent epidemiological data refer to bleeding ulcers, rather than portal hypertensive bleeding.

Therefore, we undertook the Saignements digestifs ANGH Registre Incidence Actualisée (SANGHRIA) trial to assess UGIB outcomes, in light of these new determinants by establishing a new national, multicenter cohort 10 years after the first and to identify risk factors for rebleeding and mortality.

\section{Patients and methods}

From November 2017 to October 2018, patients fulfilling the following inclusion criteria were prospectively included in 46 general hospitals in France. UGIB was defined as hematemesis and/or melena and/or acute anemia. For patients with acute anemia, the endoscopist had to find blood in the upper digestive tract (or a lesion) to confirm the patient's inclusion in the study. The patients included in the study were classified in two groups: patients admitted to Emergency Departments with UGIB symptoms (outpatients) and those already hospitalized for other reasons than UGIB (inpatients).

Patients $<18$ years old were excluded, as were those under legal guardianship. This trial was first registered with French National Agency for Medicines and Health Products Safety (ANSM ID RCB no. 2017-A01920-53) and received Ethics Committee approved (Comité de Protection des Personnes Sud Méditerranée II) in May 2017. The study was conducted in accordance with the Declaration of Helsinki, all applicable local regulations and French law. Written information was provided to all patients and they were able to accept or decline their participation by verbal non-opposition. The data were collected in an electronic case-report form and were monitored by a studydesignated Clinical Research Associate.

\section{Epidemiological, clinical and biological data}

These data were collected prospectively at the time of inclusion: age, sex, body mass index, Charlson comorbidity score [9], smoking status, alcohol consumption (excessive $>30 \mathrm{~g} /$ day), history of peptic ulcer and Helicobacter pylori status, heart rate and blood pressure at admission and the need for resuscitation. For patients with cirrhosis, its etiology, the Child-Pugh classification were noted, and the Model for End-stage Liver Disease score was calculated. Each inpatient's initial hospitalization unit was documented. Relevant treatments were recorded, such as, type of anticoagulant treatment (vitamin-K antagonist or direct oral anticoagulant), antiplatelet agents, non- 
steroidal anti-inflammatory drugs, corticosteroids, protonpump inhibitors (PPIs) and beta-blockers.

Shock was defined as systolic blood pressure $<100 \mathrm{~mm} \mathrm{Hg}$ and pulse rate $>100 /$ minute. Treatment modalities and details of blood transfusions were left to the discretion of the treating physician.

\section{Endoscopic data}

Endoscopic information was collected but also time to the procedure, presence of an endoscopic assistant, anesthesia use, calculations of the Rockall and Glasgow-Blatchford scores [10, 11] and detailed type of endoscopic treatment.

\section{Outcomes}

The following information was collected during the 6 -week follow-up period: 1) surgical or radiological intervention; 2) length of hospitalization; 3) need for transfusion; 4) rebleeding; 5) morbidity; and 6) all causes of death. Patients were followed for at least 6 weeks to know about rebleeding, readmission or death. Early rebleeding was defined as recurrent bleeding before discharge, and late rebleeding was defined as recurrent bleeding occurring between discharge and 6-week follow-up. For statistical analyses, early and late rebleeding rates were combined.

\section{Statistical analysis}

Results are expressed as mean and standard deviation [SD], or median and interquartile range (IQR) for continuous variables. Univariate analyses used a Student's t-test to compare quantitative variables and the chi-squared test or Fisher's exact test for qualitative variables. Step-wise logistic-regression analysis identified factors predictive of rebleeding and mortality. Significant variables with $P \leq 0.20$ in univariate analyses were included in the stepwise logistic-regression multivariate model. The odds ratio (OR) and $95 \%$ confidence interval $(\mathrm{Cl})$ were calculated for each independent factor. A two-tailed $P<0.05$ defined statistical significance. Statistical analyses were computed with SPSS software (version 18).

\section{Results}

During the study period, 2536 patients were initially enrolled and, after excluding 38 for missing essential data, 2498 remained for analysis (1677 men and 821 women; mean age 68.5 [16.3] years) ( Fig. 1). Among them, 1864 (74.5\%) were outpatients and 634 (25.5\%) were inpatients.

\section{Study population}

Baseline characteristics are reported in $>$ Table 1. Among the 524 patients (20.9\%) with known cirrhosis, $22.5 \%$ were ChildPugh classification stage C. Origin of cirrhosis was alcoholism for $80.0 \%$ of them, non-alcoholic steatohepatitis for $9.0 \%$ and viral hepatitis infection for $4.2 \%$.

Melena, associated or not with other inclusion criteria, was present in $73.9 \%$ of the patients. At admission, mean systolic blood pressure was 120 [26.4] mmHg and mean pulse rate was 92 [20.5] beats/minute.
2536 Patients 46 Hospitals

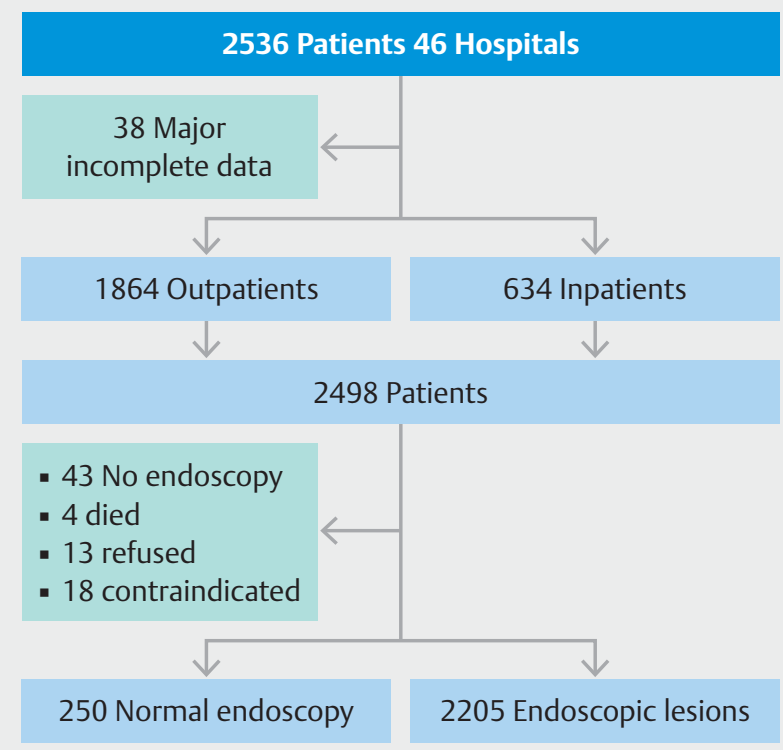

Fig. 1 Flowchart of the population.

Medications with a potential bleeding risk being taken at admission are summarized in $>$ Table 2 . At first consultation, 777 patients $(31.1 \%)$ had ongoing PPIs. Beta-blockers were prescribed for 195 cirrhotic patients (37.2\%), mainly propranolol for $125(64.1 \%)$.

\section{Initial management}

All patients had a saline or other infusion for endoscopy but the hemodynamic status of only 700 of 2498 (28.0\%) required intensive resuscitation with isotonic, intravenous (IV) fluid support before upper endoscopy; 257 of 2498 (10.3\%) were in shock. Initial red blood-cell transfusion(s) were given to 1214 patients $(48.6 \%)$. The mean initial hemoglobin level of the 1214 patients who received blood transfusion(s) was 7 [1.6] g/ $\mathrm{dL}$; among them, 312 (25.7\%) had hemoglobin levels $\geq 8 \mathrm{~g} / \mathrm{dL}$ and $54(4.4 \%)$ had levels $\geq 10 \mathrm{~g} / \mathrm{dL}$. The mean number of units was $2.36(1.09)$ and the median hemoglobin level at endoscopy was $9 \mathrm{~g} / \mathrm{dL}$ (IQR 7.9-10.6).

Among patients with portal hypertension and rebleeding, the initial transfusion rate did not differ according to when the bleeding event occurred or not (51.1\% vs $48.9 \%$ respectively; $P$ $=0.28$ ), the total mean number of red cell units transfused into rebleeders was higher than for non-bleeders (4.1 [2.8] vs 2.9 [1.5] respectively; $P<0.0001)$. Deceased patients with portal hypertension had a higher initial transfusion rate than survivors (57.3\% vs $42.7 \%$, respectively; $P=0.029$ ) and a higher total mean number of units transfused (3.6 [2.5] vs 3.0 [1.7], respectively; $P=0.039)$.

Coagulopathy reversion was needed for 297 patients (11.9\%), most frequently with vitamin K (108/297, $36.5 \%)$ or fresh-frozen plasma (101/297, 34.1\%). IV PPIs were initiated for 2114 patients ( $84.8 \%$ ) prior to endoscopy, most often with an 80 -mg infusion, followed by $8 \mathrm{mg}$ per hour continuous infu- 
- Table 1 Study population: demographic and clinical characteristics, and laboratory findings.

\begin{tabular}{|c|c|c|}
\hline Characteristic & $\begin{array}{l}\text { Data } \\
\text { available }\end{array}$ & Value $^{1}$ \\
\hline \multicolumn{3}{|l|}{ Clinical } \\
\hline - $\operatorname{Sex}(M / F)$ & 2498 & $\begin{array}{l}1677(67.1) / \\
821(32.9)\end{array}$ \\
\hline - Age (years) & 2498 & $68.5[16.3]$ \\
\hline . >75 years & & $954(38.2)$ \\
\hline - Body mass index & $2327 / 2498$ & $25.9[5.7]$ \\
\hline - Cirrhosis & $2497 / 2498$ & $524(20.9)$ \\
\hline - Child-Pugh score & $464 / 524$ & $8.38[2.3]$ \\
\hline $\begin{array}{l}\text { Model for end-stage liver } \\
\text { disease score }\end{array}$ & $433 / 524$ & $15.9[6.9]$ \\
\hline - Charlson score & $2497 / 2498$ & $2.71[2.5]$ \\
\hline - Glasgow-Blatchford score & $2417 / 2498$ & $10.3[4.4]$ \\
\hline $\begin{array}{l}\text { - Excessive alcohol consump- } \\
\text { tion }\end{array}$ & $2469 / 2498$ & $630(25.5)$ \\
\hline \multicolumn{3}{|l|}{ Laboratory } \\
\hline $\begin{array}{l}\text { - Hemoglobin at admission, } \\
\text { g/dL }\end{array}$ & $2488 / 2498$ & $9[2.9]$ \\
\hline $\begin{array}{l}\text { - Hemoglobin at endoscopy, } \\
\mathrm{g} / \mathrm{dL}\end{array}$ & $2481 / 2498$ & $9.47[2.3]$ \\
\hline $\begin{array}{l}\text { - Lowest hemoglobin level } \\
\text { during hospitalization, g/dL }\end{array}$ & $2469 / 2498$ & $8.2[2.97]$ \\
\hline $\begin{array}{l}\text { - Prothrombin rate (only cir- } \\
\text { rhotic patients), \% }\end{array}$ & $519 / 524$ & $54.8[18.5]$ \\
\hline $\begin{array}{l}\text { - Prothrombin rate at endos- } \\
\text { copy (all patients), \% }\end{array}$ & $2376 / 2498$ & $70[22]$ \\
\hline - Factor V, \% & $298 / 524$ & $61.9[24.1]$ \\
\hline - Platelets, $/ \mathrm{mm}^{3}$ & $2479 / 2498$ & $\begin{array}{l}221258 \\
{[119156]}\end{array}$ \\
\hline $\begin{array}{l}\text { - Bilirubin (only cirrhotic pa- } \\
\text { tients), } \mu \mathrm{mol} / \mathrm{L}\end{array}$ & $518 / 524$ & $44.8[60.5]$ \\
\hline - Creatinine, $\mu \mathrm{mol} / \mathrm{L}$ & $960 / 2498$ & $111.4[78.1]$ \\
\hline - Urea, mmol/L & $2455 / 2498$ & $14.1[11.2]$ \\
\hline $\begin{array}{l}\text { - Albumin (only cirrhotic pa- } \\
\text { tients), g/L }\end{array}$ & $464 / 524$ & $28.5[6.5]$ \\
\hline $\begin{array}{l}{ }^{1} \text { Categorical variables are express } \\
\text { variables as mean [standard devi }\end{array}$ & lumber (per & ); continuous \\
\hline
\end{tabular}

sion for 1261 (59.8\%). Octreotide or terlipressin was prescribed for 639 patients (25.6\%) (administered in the Emergency Department just before endoscopy).

\section{Endoscopic procedure and results}

Among the 2455 endoscopies (98.3\%) performed, 2067 (83.4\%) were done within 24 hours after arrival in the Emergency Department for outpatients or after learning of the
- Table 2 Drugs being taken at admission with a potential risk of causing upper gastrointestinal bleeding.

\begin{tabular}{|l|l|}
\hline Treatment & $\mathbf{n} / \mathbf{2 4 9 8}(\%)$ \\
\hline Nonsteroidal anti-inflammatory drugs alone & $172(6.9)$ \\
\hline Aspirin alone & $527(21.1)$ \\
\hline Antiplatelet alone & $189(7.6)$ \\
\hline Oral anticoagulant alone or in combination & $489(19.6)$ \\
\hline - Vitamin K antagonist & $267(54.6)$ \\
\hline - Direct oral anticoagulant & $208(42.5)$ \\
\hline - Missing data & $14(2.9)$ \\
\hline Aspirin + antiplatelet & $135(5.4)$ \\
\hline Aspirin + anticoagulant & $115(4.6)$ \\
\hline Antiplatelet+anticoagulant & $36(1.4)$ \\
\hline Aspirin + antiplatelet+anticoagulant & $20(0.8)$ \\
\hline None of the above & $928(37.1)$ \\
\hline
\end{tabular}

bleeding for inpatients, with prior IV erythromycin administration for $545(21.9 \%)$. \%). Endoscopy was done within 24 hours for $92.9 \%$ of the patients with shock and $82.2 \%$ of those without $(P<0.0001)$. Among all of them, endoscopy was performed within 6 hours in $52.5 \%$ of patients with shock and $30.9 \%$ of those without shock $(P<0.0001)$. A senior physician performed $83.1 \%$ of the procedures, with an endoscopic assistant for 2248 patients (91.7\%) (most often a specialized nurse) and the percentages of endoscopy assistants available were similar for endoscopies done on weekdays or during weekends. General anesthesia was given to $30.9 \%$ of the patients, $60.1 \%$ of whom were intubated. The endoscopist had access to a water pump during $84.9 \%$ of the examinations, and endoscopy quality was considered satisfactory for $84.6 \%$, moderately satisfactory for $9.9 \%$ and unsatisfactory for $3.3 \%$ (with $2.3 \%$ missing data).

Forty-three patients did not undergo endoscopy: 18 had a contraindication, 13 refused, four patients died before endoscopy, one was transferred, and data were missing for seven. Endoscopy was considered normal for 250.

The lesions diagnosed and main causes of bleeding, detailed in $>$ Table 3, were: 1) peptic ulcers and gastroduodenal ulcers or erosions $(44.9 \%) ; 2$ ) related to portal hypertension $(18.9 \%)$; and 3 ) esophagitis $(11.4 \%)$. The median Rockall score was 5 (IQR 3-6). Among patients with portal hypertension-related bleeding, 160 (23.4\%) were newly diagnosed with cirrhosis during the endoscopy.

\section{Outcomes}

A median of 3 red blood-cell units (IQR 2-4) were transfused during hospitalization. UGIB required a radiological intervention: embolization for 23 patients $(0.9 \%)$ and a transjugular intrahepatic portosystemic shunt for $20(0.8 \%)$. Sixty-seven patients $(2.7 \%)$ required surgery. 
- Table 3 Type of lesions and main causes of bleeding.

\begin{tabular}{|c|c|c|}
\hline Type of lesion ${ }^{1}$ & $n / N$ & $\begin{array}{l}\text { Main cause of } \\
\text { bleeding }(/ 2205)^{2}\end{array}$ \\
\hline Ulcers or erosions & |1145 & $990(44.9)$ \\
\hline Esophageal & $121(10.6)$ & 99 \\
\hline Gastric & $437(38.2)$ & 372 \\
\hline Duodenal & $587(51.3)$ & 519 \\
\hline Forrest classification & 1417 & \\
\hline la & $8(1.9)$ & \\
\hline $\mathrm{Ib}$ & $47(11.3)$ & \\
\hline Ila & $28(6.7)$ & \\
\hline IIb & $56(13.4)$ & \\
\hline IIc & $62(14.9)$ & \\
\hline III & $216(51.8)$ & \\
\hline Portal hypertension & |684 & $416(18.9)$ \\
\hline Esophageal varices & $419(61.3)$ & 313 \\
\hline Gastric varices & $47(6.9)$ & 36 \\
\hline Gastropathy & $215(31.4)$ & 64 \\
\hline Duodenal varices & $3(0.4)$ & 3 \\
\hline Esophageal varix classification & /411 & \\
\hline Grade 1 & $81(19.7)$ & \\
\hline Grade 2 & $198(48.2)$ & \\
\hline Grade 3 & $132(32.1)$ & \\
\hline Esophagitis & /396 & $251(11.4)$ \\
\hline Peptic & $380(96)$ & \\
\hline Caustic & $4(1)$ & \\
\hline Post-radiotherapy & $4(1)$ & \\
\hline Unknown & $8(2)$ & \\
\hline Cancer & |121 & $115(5.2)$ \\
\hline Esophageal & $31(25.6)$ & 29 \\
\hline Gastric & $65(53.7)$ & 62 \\
\hline Duodenal & $25(20.7)$ & 24 \\
\hline Vascular & $\mid 121$ & $94(4.3)$ \\
\hline Esophageal & $3(2.5)$ & 1 \\
\hline Gastric & $71(58.7)$ & 56 \\
\hline Duodenal & $47(38.8)$ & 37 \\
\hline Mallory-Weiss syndrome & 190 & $86(3.9)$ \\
\hline $\begin{array}{l}\text { Delayed bleeding/sloughing } \\
\text { scab }^{3}\end{array}$ & $\mid 23$ & $22(1)$ \\
\hline Dieulafoy's lesion & $\mid 21$ & $21(1)$ \\
\hline Others & 1336 & $196(8.9)$ \\
\hline Esophageal foreign body & $1(0.3)$ & 1 \\
\hline
\end{tabular}

- Table 3 (Continuation)

\begin{tabular}{|c|c|c|}
\hline Type of lesion ${ }^{1}$ & $n / N$ & $\begin{array}{l}\text { Main cause of } \\
\text { bleeding }(/ 2205)^{2}\end{array}$ \\
\hline Esophagus & $34(10.1)$ & 16 \\
\hline Gastric & $196(58.3)$ & 127 \\
\hline Duodenal & $105(31.3)$ & 52 \\
\hline Missing data & & $14(0.5)$ \\
\hline Total & & $2205(100)$ \\
\hline Normal endoscopy & $250 / 2455$ & - \\
\hline \multicolumn{3}{|c|}{$\begin{array}{l}\text { Values are expressed as number (percentages) of available data. } \\
1 \text { Patients could have multiple lesions. } \\
{ }^{2} \text { According to the treating physician's opinion. } \\
{ }^{3} \text { Sloughing scab, defined as dead tissue detaching from a lesion, corre- } \\
\text { sponds to an ulceration bleeding after band ligation or polypectomy. }\end{array}$} \\
\hline
\end{tabular}

Post-endoscopy hospitalization lasted a median of 7 days (IQR 4-12). Notably, 1042 patients needed an extension of hospitalization (defined as a length of stay longer than that of the duration of the initial critical care treatment period) that was linked to UGIB for 297 patients or unrelated to UGIB for 745. Among the reasons associated with UGIB, most were because of liver failure (67/297, 22.6\%), cancer diagnosis (47/297, $15.8 \%)$ and multiorgan failure (29/297, 9.8\%). The most frequent unrelated UGIB reasons for prolonged hospitalization were comorbidities (549/745, 73.8\%), waiting for convalescent care $(106 / 745,14.2 \%)$ and waiting for transfer to another hospital $(89 / 745,12.0 \%)$. The prolonged hospitalizations of $61 \mathrm{pa}-$ tients were linked to UGIB and another cause or unknown data.

\section{Rebleeding, rehospitalization and mortality}

During hospitalization, 259 patients (10.5\%) experienced rebleeding; the median time to rebleeding was 2 days (IQR 1-5). Late rebleeding occurred in 158 patients (6.6\%), at a median of 17 days (IQR 7-30). Predictors significantly and independently associated with rebleeding, detailed in $>$ Table 4 , were being an inpatient, Glasgow-Blatchford score $>11$ or active bleeding, while oral anticoagulant treatment was found to be protective against recurrent bleeding.

Mortality during hospitalization was $8.6 \%$ (214 patients) and was significantly lower for outpatients than inpatients ( $5.8 \%$ vs $16.8 \%$, respectively $(P<0.0001)$; OR 3.26; $95 \% \mathrm{Cl} 2.45-4.33)$. Eighty-six patients died after discharge, for a 6-week mortality rate of $12.5 \%$ ( $9.1 \%$ of outpatients vs $22.2 \%$ of inpatients ( $P<$ $0.0001)$; OR $0.35 ; 95 \% \mathrm{Cl} 0.27-0.45$ ). The main causes of death during the initial hospitalization were multiorgan failure for 64 patients $(29.6 \%)$, directly related to the UGIB for $40(18.5 \%)$, cancer for $34(15.7 \%)$, liver dysfunction for $24(11.1 \%)$, heart or lung failure for 17 (7.9\%) and infection for $16(7.4 \%)$. Factors significantly and independently associated with the 6-week mortality, detailed in $>$ Table 4 , were initial transfusion, Charlson score $>4$, Rockall score $>5$, being an inpatient or rebleeding. 
- Table4 Multivariate analyses of factors predictive of rebleeding or mortality.

\begin{tabular}{|c|c|c|c|}
\hline Factor & Pvalue & $\begin{array}{l}\text { Odds } \\
\text { ratio }\end{array}$ & $95 \% \mathrm{Cl}$ \\
\hline \multicolumn{4}{|l|}{ Rebleeding } \\
\hline Oral anticoagulant & 0.028 & 0.67 & $0.47-0.96$ \\
\hline Being an inpatient & 0.028 & 1.36 & $1.03-1.79$ \\
\hline $\begin{array}{l}\text { Glasgow-Blatchford } \\
\text { score }>11\end{array}$ & 0.011 & 1.45 & $1.09-1.95$ \\
\hline Active bleeding & 0.0001 & 1.95 & $1.48-2.56$ \\
\hline \multicolumn{4}{|l|}{ Mortality } \\
\hline $\begin{array}{l}\text { Red blood cell transfusion } \\
\text { during resuscitation }\end{array}$ & 0.031 & 1.54 & $1.04-2.28$ \\
\hline Charlson score $>4$ & 0.0001 & 1.80 & $1.31-2.48$ \\
\hline Rockall score > 5 & 0.0001 & 1.98 & $1.39-2.80$ \\
\hline Being an inpatient & 0.0001 & 2.45 & $1.76-3.41$ \\
\hline Rebleeding & 0.0001 & 2.6 & $1.85-3.64$ \\
\hline
\end{tabular}

Descriptive data from the 2005 study exclusively on outpatients are reported in $>$ Table 5 , along with those from outpatients included in the SANGHRIA trial.

\section{Discussion}

Among the 2498 outpatients and inpatients with UGIB included in the SANGHRIA trial, $83.4 \%$ underwent endoscopy within 24 hours that revealed an ulcer in $44.9 \%$ and portal hypertension in $18.9 \%$. Early rebleeding occurred in $10.5 \%$ of them. The $6-$ week follow-up mortality was $12.5 \%$. Mortality differed significantly between outpatients (9.1\%) and inpatients (22.2\%). The main predictors significantly associated with rebleeding and mortality were initial active bleeding and rebleeding.

From an epidemiological point of view, the SANGHRIA-trial results showed that the main causes of UGIB were peptic ulcers or gastroduodenal ulcers or erosions (44.9\%) and portal hypertension-related lesions (18.9\%). Those results indicated that portal hypertension lesions are quite frequent in France. Notably, in the United Kingdom, peptic ulcers accounted for $36 \%$ of UGIB and bleeding varices for $11 \%$ [12], whereas in Turkey, gastric or duodenal ulcers were estimated at $32 \%$ and esophageal varices at $4.9 \%$ [13]. According to the most recent study in Hong Kong [6], peptic ulcers were diagnosed in $61.4 \%$ of patients and esophageal or gastric varices in $8.5 \%$. It is worth emphasizing that cancer was the fourth cause of UGIB herein (only $5.2 \%$ of cases) but was the cause of death for $15.7 \%$. A Brazilian study [14] also reported this poor prognosis and concluded that UGIB in this patient population must be seen as a lifethreatening event.

One of our objectives was to determine whether UGIB management had improved over the past decade. The European Society of Gastrointestinal Endoscopy issued strong recommen-
- Table 5 Descriptive data from our two studies conducted 13 years apart.

\begin{tabular}{|l|l|l|}
\hline Parameter & $\begin{array}{l}\mathbf{2 0 0 5} \text { (out- } \\
\text { patients }\end{array}$ & $\begin{array}{l}\mathbf{2 0 1 8} \text { (only } \\
\text { outpatients) }\end{array}$ \\
\hline Clinical data & & \\
\hline - Age (years), mean (SD) & $63.3(18.2)$ & $67.2(16.8)$ \\
\hline - Cirrhosis & $31.9 \%$ & $22.5 \%$ \\
\hline Endoscopic features & & \\
\hline - Peptic ulcer disease & $36.9 \%$ & $44.4 \%$ \\
\hline - Varices and portal hyperten- & $24.5 \%$ & $21.9 \%$ \\
\hline sive gastropathy & & $8.6(9.1)$ \\
\hline - Hospital stay (days), mean (SD) & $9.2(13.5)$ & $9.2 \%$ \\
\hline " Rebleeding & $9.9 \%$ & $3.8 \%$ \\
\hline " Surgery & $3 \%$ & $5.8 \%$ \\
\hline - Hospital mortality & $8.3 \%$ & \\
\hline 1 Nahon et al. [7]. & & \\
\hline
\end{tabular}

dations concerning the time to endoscopy and the use of erythromycin [1]; in our study, $83.4 \%$ of endoscopies were done within 24 hours vs. $79 \%$ in 2005 [7], and after erythromycin infusion for $21.9 \%$ vs. $14 \%$ of patients, respectively. In comparison, endoscopy within 24 hours of admission (early endoscopy) was only achieved in $58.9 \%$ in a recent UK prospective, multicenter audit [15]. Multivariable analyses in that study showed that independent predictors of delayed endoscopy were lower Glasgow-Blatchford scores, late referral and admissions between 7:00 and 19:00 hours or via the Emergency Department. In that UK audit, early endoscopy was associated with shorter lengths of stay (median difference 1 day; $P=0.004$ ) but not with lower 30 -day mortality $(P=0.34)$. That latter point warrants further commentary. In our study, too, the time to endoscopy was not associated with mortality in our multivariate analysis. In contrast, a recent large Danish nationwide cohort study, focusing on peptic ulcer bleeding, found that the time to endoscopy was associated with mortality in patients with an American Society of Anesthesiologists score of 3 to 5 or hemodynamic instability [16]. For patients in stable condition, Lau et al. reported that urgent endoscopy ( $<6$ hours) did not lower mortality, compared with early endoscopy (6-24 hours) [6].

A new major point of the most recent international recommendations is to limit the number of red blood-cell units transfused prior to endoscopy $[1,17]$. In our previous study, $63 \%$ of patients received transfusion(s) [7], with a mean number of 3.8 \pm 2.6 transfused units, whereas in SANGHRIA trial, only $48.6 \%$ of the patients received initial red blood-cell transfusion(s), for a lower mean of $2.4 \pm 1.1$ units transfused. Because our SANGHRIA population (in- and outpatients) differed from that of our earlier study (only outpatients) and these studies were not randomized, it is difficult to conclude definitively about the link between over-transfusion and rebleeding or mortality. In our previous study, among patients who received red blood cell 
transfusion(s), rebleeding (OR 11.3; $95 \% \mathrm{Cl} 7.0-18.3$ ), surgery (OR 5.8; $95 \% \mathrm{Cl} 2.9-11.6)$, and mortality (2.2; 1.6-2.9) were significantly more frequent than among those not transfused. In the SANGHRIA trial, patients with portal hypertension and rebleeding received significantly more red cell units, and patients who died had received initial transfusion(s) more often and had a higher mean number of units transfused than survivors. Thus, the transfusion rate could not have been a causal factor of death or recurrence in these patients. At most, excess transfusions to achieve $>9 \mathrm{~g} / \mathrm{dL}$ of hemoglobin can be considered an additional sign of a pejorative outcome, as documented in randomized studies [17]. This restrictive transfusion-strategy recommendation is probably the one most followed: in a 2011 UK study only $43 \%$ of patients were transfused [12] and Lau et al. administered a mean of 2.4 red blood-cell units transfused for urgent and early endoscopy groups [6].

Not many recommendations address the endoscopy procedure's environment, for example, general anesthesia or the presence of an endoscopy assistant. Those from the American Society for Gastrointestinal Endoscopy concerning variceal hemorrhage recommend intubating patients before the procedure and the international consensus guidelines on the management of patients with non-variceal UGIB recommend having support staff trained to assist in endoscopy available on an urgent basis, as do the European Association for the Study of the Liver recommendations $[3,4,18]$. In the SANGHRIA trial, $30.9 \%$ of endoscopies were done under general anesthesia vs. $12.5 \%$ in 2005. An endoscopy assistant (85\% of whom were specialized nurses) was present during $91.7 \%$ of those interventions and the percentages were similar for endoscopies done on weekdays or during weekends, whereas in 2005, those rates were $85 \%$ on weekdays and $40 \%$ on weekends. To our knowledge, no data on this is item are available from recent, nationwide, cohort studies or audits of daily practice.

These findings about the few items discussed above could lead us to think that endoscopic practices have improved over the past decade.

In the SANGHRIA trial, despite persistently high mortality rates during hospitalization or at 6-week follow-up (8.6\% and $12.5 \%$, respectively), with inpatients and outpatients differing significantly, comparison of SANGHRIA outpatients and our previous study (hospital mortality of outpatients) tended to show that this rate declined: $5.8 \%$ vs. $8.3 \%$, respectively. That observation was supported by other analyses during a decade concerning both non-variceal or variceal bleeding in UK inpatients or outpatients [19]. Regarding SANGHRIA-trial overall mortality, it seems to be the same or slightly lower than those from other European studies [12, 19, 20].

The two most frequent causes of death in this study were multiorgan failure (29.6\%), followed by those directly UGIBrelated $(18.5 \%)$. Those observations might be explained by having included inpatients with greater fragility and more comorbidities could be responsible for multiorgan failure, as found by others who focused on peptic ulcer bleeding in an outpatient-and-inpatient cohort [21]. Lowering the mortality rate must therefore also involve optimizing the management of comorbidities.
Our multivariate analyses on potential predictors significantly associated with rebleeding or 6-week mortality confirmed the validity and power of classical scores, e. g., a Glasgow-Blatchford score $>11$ for rebleeding and Charlson score $>4$ or Rockall score $>5$ for mortality. The results of other studies also confirmed the performances of the Glasgow-Blatchford or Rockall scores [22] but their complicated calculations limit their implementation in daily clinical practice. Hence, some new scores have been developed, like the UGIB-risk AIMS65 [23], whose calculation is much easier for at least equivalent performance, especially to predict mortality [24,25]. We did not use the AIMS65 because it was insufficiently known when we designed our trial.

\section{Strengths and limitations}

We enrolled a large number of patients in this 1-year, prospective, multicenter trial. Moreover, we had the opportunity to compare inpatients and outpatients, whereas our previous study focused only on outpatients, which represents a real plus. This "real-life" study provided an overview of medical care in French general hospitals (not university centers) that tried to overcome the weaknesses highlighted by of our earlier study [7]. Nahon et al. suggested that it would have been of interest to have information about survival during the 30-day post-endoscopy period and to study early morbidity and mortality rates after hospital discharge [7]. Indeed, studies like ours are sorely lacking in the available literature. Most authors focused their investigations on non-variceal UGIB and/or conducted them in tertiary center(s) and/or without precise endoscopic data and/or sufficiently long follow-up.

The large number of patients included in the SANGHRIA trial provided a database rich in information about daily life, which is usually not available in academic studies. We enrolled inpatients and outpatients, who were followed for at least 6 weeks, thereby providing key advances in our understanding of UGIB.

The design of our study was not optimum for statistical analyses (no randomized analysis) and, because no inpatients were included in our previous study [7], comparison was limited to outpatients and descriptive remarks.

\section{Conclusions}

Although a direct comparison was not possible, the results of this trial highlighted the trend towards improved UGIB management compared to those conducted previously, especially for outpatients. Despite this improvement, mortality at 6week follow-up remained high, especially for patients who experienced UGIB while they were hospitalized for another reason. This persistently high mortality can be explained by the severity of the underlying disease for which patients were initially admitted. Strong predictors of mortality were in-hospital bleeding and rebleeding, with no major role of anticoagulation therapy. These findings confirmed that previously known predictors were still valid, even after taking into account the recent advances in management of patients with UGIB. 


\section{Acknowledgements}

The French National Society of Gastroenterology (SNFGE) Fonds d'Aide à la Recherche et à l'Evaluation (FARE) provided a grant for this research. The authors thank Ms. Catherine Bellot and Ms. Marie-Cécile Hervé of the Clinical Research Unit, Centre Hospitalier Saint-Brieuc and Guillaume Bouguen, MD, PhD, of the Centre Hospitalier Universitaire de Rennes

\section{Competing interests}

Dr. Nahon has received lecture fees from MSD, Takeda and Sandoz, and consulting fees from MSD, Takeda, Janssen, Sandoz, Ferring, and Vifor. Dr. Arotcarena has received funds from Gilead and Abbvie to attend meetings. Dr. Macaigne has received funding from Jansen, Takeda, Abbvie, and Tillots to attend meetings.

\section{References}

[1] Gralnek I, Dumonceau J-M, Kuipers E et al. Diagnosis and management of nonvariceal upper gastrointestinal hemorrhage: European Society of Gastrointestinal Endoscopy (ESGE) Guideline. Endoscopy 2015; 47: a1-46

[2] Hwang JH, Fisher DA, Ben-Menachem T et al. The role of endoscopy in the management of acute non-variceal upper Gl bleeding. Gastrointest Endosc 2012; 75: 1132-1138

[3] Hwang JH, Shergill AK, Acosta RD et al. The role of endoscopy in the management of variceal hemorrhage. Gastrointest Endosc 2014; 80: 221-227

[4] de Franchis R. Expanding consensus in portal hypertension. J Hepatol 2015; 63: 743-752

[5] Sey MSL, Mohammed SB, Brahmania M et al. Comparative outcomes in patients with ulcer- vs non-ulcer-related acute upper gastrointestinal bleeding in the United Kingdom: a nationwide cohort of 4474 patients. Aliment Pharmacol Ther 2019; 49: 537-545

[6] Lau JYW, Yu Y, Tang RSY et al. Timing of Endoscopy for Acute Upper Gastrointestinal Bleeding. N Engl J Med 2020; 382: 1299-1308

[7] Nahon S, Hagège $H$, Latrive JP et al. Epidemiological and prognostic factors involved in upper gastrointestinal bleeding: results of a French prospective multicenter study. Endoscopy 2012; 44: 998-1008

[8] Zeitoun J-D, Rosa-Hézode I, Chryssostalis A et al. Epidemiology and adherence to guidelines on the management of bleeding peptic ulcer: a prospective multicenter observational study in 1140 patients. Clin Res Hepatol Gastroenterol 2012; 36: 227-234

[9] Charlson ME, Pompei P, Ales KL et al. A new method of classifying prognostic comorbidity in longitudinal studies: Development and validation. J Chronic Dis 1987; 40: 373-383

[10] Rockall TA, Logan RF, Devlin HB et al. Risk assessment after acute upper gastrointestinal haemorrhage. Gut 1996; 38: 316-321
[11] Blatchford O, Murray WR, Blatchford M. A risk score to predict need for treatment for upper-gastrointestinal haemorrhage. Lancet Lond Engl 2000; 356: 1318-1321

[12] Hearnshaw SA, Logan RFA, Lowe D et al. Acute upper gastrointestinal bleeding in the UK: patient characteristics, diagnoses and outcomes in the 2007 UK audit. Gut 2011; 60: 1327-1335

[13] Kaya E, Karaca MA, Aldemir D et al. Predictors of poor outcome in gastrointestinal bleeding in emergency department. World J Gastroenterol 2016; 22: 4219

[14] Maluf-Filho F, da Martins B C, de Lima MS et al. Etiology, endoscopic management and mortality of upper gastrointestinal bleeding in patients with cancer. United Eur Gastroenterol J 2013; 1: 60-67

[15] Siau K, Hodson J, Ingram R et al. Time to endoscopy for acute upper gastrointestinal bleeding: Results from a prospective multicentre trainee-led audit. United Eur Gastroenterol J 2019; 7: 199-209

[16] Laursen SB, Leontiadis GI, Stanley AJ et al. Relationship between timing of endoscopy and mortality in patients with peptic ulcer bleeding: a nationwide cohort study. Gastrointest Endosc 2017; 85: 936-944. e3

[17] Villanueva C, Colomo A, Bosch A et al. Transfusion Strategies for Acute Upper Gastrointestinal Bleeding. N Engl J Med 2013; 368: 1121

[18] Barkun AN, Bardou M, Kuipers EJ et al. International consensus recommendations on the management of patients with nonvariceal upper gastrointestinal bleeding. Ann Intern Med 2010; 152: 101-113

[19] Crooks C, Card T, West J. Reductions in 28-day mortality following hospital admission for upper gastrointestinal hemorrhage. Gastroenterology 2011; 141: 62-70

[20] Rosenstock S], Møller MH, Larsson H et al. Improving Quality of care in peptic ulcer bleeding: nationwide cohort study of 13,498 consecutive patients in the Danish Cinical Register of Emergency Surgery. Am J Gastroenterol 2013; 108: 1449-1457

[21] Sung JJY, Tsoi KKF, Ma TKW et al. Causes of mortality in patients with peptic ulcer bleeding: a prospective cohort study of 10,428 cases. Am J Gastroenterol 2010; 105: 84-89

[22] Bryant RV, Kuo P, Williamson K et al. Performance of the GlasgowBlatchford score in predicting clinical outcomes and intervention in hospitalized patients with upper GI bleeding. Gastrointest Endosc 2013; 78: 576-583

[23] Saltzman JR, Tabak YP, Hyett BH et al. A simple risk score accurately predicts in-hospital mortality, length of stay, and cost in acute upper Gl bleeding. Gastrointest Endosc 2011; 74: 1215-1224

[24] Robertson M, Majumdar A, Boyapati R et al. Risk stratification in acute upper GI bleeding: comparison of the AIMS65 score with the Glasgow-Blatchford and Rockall scoring systems. Gastrointest Endosc 2016; 83: 1151-1160

[25] Martínez-Cara JG, Jiménez-Rosales R, Úbeda-Muñoz M et al. Comparison of AIMS65, Glasgow-Blatchford score, and Rockall score in a European series of patients with upper gastrointestinal bleeding: performance when predicting in-hospital and delayed mortality. United Eur Gastroenterol J 2016; 4: 371-379 